\title{
Impact of Engineering Faculty Participation in Decision Makingand Commitment on Organizational Citizenship Behaviour
}

\author{
S. Pavan Kumar \\ Assistant Professor \\ Department of Humanities, Social Sciences and Management \\ National Institute of Technology Karnataka, Surathkal \\ pavankumar@nitk.ac.in \\ e-mail:saraf_pavan@rediffmail.com
}

Vijai N. Giri

Head \& Professor

Department of Humanities and Social Sciences

Indian Institute of Technology Kharagpur

Kharagpur-721302 (W.B.)

e-mail:vng@hss.iitkgp.ernet.in

\begin{abstract}
The standard of educational institutions depends mainly on such teachers who are willing to exert significant efforts beyond their formal job requirements. The present study examined the impact of teachers' participation in decision making and commitment on organizational citizenship behaviour. Data were collected from 655 teachers working in private engineering colleges, affiliated to Jawaharlal Nehru Technological University Hyderabad, India. Results revealed that participation in technical decisions played important role in predicting organizational citizenship behaviour towards team, and organization. Participation in managerial decisions played significant role in predicting organizational citizenship behaviour towards students, and organization. Apart from the participation in decision making, commitment variables were also identified as predictors of the organizational citizenship behaviour. Affective organizational commitment predicted organizational citizenship behaviour towards organization. Job
\end{abstract}

Dr. S. Pavan Kumar

Assistant Professor

Department of Humanities, Social Sciences and Management National Institute of Technology Karnataka, Surathkal

Phone: +91-7760020200 (Mobile),

pavankumar@nitk.ac.in

e-mail:saraf_pavan@rediffmail.com involvement had significant effect on organizational citizenship behaviour towards students. Group commitment predicted both organizational citizenship behaviour towards team, and organization. Further, results indicated that participation in technical decisions predicted significantly all the forms of commitments such as, affective organizational commitment, job involvement, and group commitment. The study portrayed the interrelationships among the commitment forms. The findings help understand the process that explains how participation in decision making is related to organizational citizenship behaviour.

Key words: Participation in decision making, affective organizational commitment, job involvement, group commitment, organizational citizenship behaviour, student, team, organization

\section{Introduction}

The Government of India has been encouraging the spread of technical education in recent years, believing that new technologies will contribute to develop society and the country substantially. There has been a sharp increase in the number of private engineering colleges as well as universities in India with the status of either deemed to be universities or private universities. According to Umashankar and Dutta[41], higher education is expanding, but mostly in an unplanned manner, without even minimum 
levels of checks and balances. Some of the institutions maintain their standards, whereas most of the institutions are struggling to achieve the required standard. Thus, it becomes essential to look critically into the present trends in engineering education to ensure its effectiveness to face the challenges of the 21 st century in this era of globalization.

What should guide the technical institutions in order to achieve effectiveness? The effective position of an educational institution depends mainly on its consistent principles, best practices and healthy working conditions.The sense of healthy working condition is linked with teachers' attitude and interest towards innovative teaching methods, students and colleagues wellbeing, and institutions value system, etc. One of the concepts that determine the teachers' interest towards the institution is commitment. Teachers who experience positive exchanges with the institution, the teaching job, or the work group will respond with higher level of commitment. The outcomes of commitment are quite apparent. A teacher committed to the institution would like to remain with the institution and invest more effort in realizing the institutional goal.

Empowerment has its place in high performance human resource management practices. Teachers' empowerment has been studied in relation to participation in decision making [44]. Empowering teachers to participate in decision making develops the sense of fairness and trust in the institution and its operations. Fairness and trust are expected to elevate teachers' willingness to engage in organizational citizenship behaviour(OCB).

It is difficult to put entire array of teachers' job role on the formal job description. There are always some undefined areas where teachers are expected to perform. Hence, educational institutions have to be dependent on teachers who are willing to exert significant effort beyond formal job requirements, that is, to engage in OCB [36]. OCB is considered as one of the key factors for performance in educational institutions [15]. Thus, the present study focuses on the process how participation in decision making is related to OCB.

\section{Literature Review}

Literature suggests that several studies examined the relationship between participation in decision making and organizational commitment. There is hardly any study that addressed the relationship between participation in decision making and commitments such as job involvement, and group commitment.

Some research has reported conflicting evidence regarding the relationship between commitment and OCB. On one hand, Schappe[31] indicated a positive relationship between organizational commitment and OCB. On the other hand, Williams and Anderson [44] found no significant relationship. Diefendorff, Brown, Kamin, and Lord [11] stated that no published studies examining the relationship between job involvement and OCB were found previously. The two studies prior to Diefendorff et al. [11] that uncovered job involvement and OCB relationship are by Munene [27], and Somers and Birnbaum [37]. Both the studies reported a positive correlation between job involvement and OCB. The study by Cohen [11] found positive relationship between job involvement, group commitment and OCB altruism.

A. Teachers' Participation in Decision Making and Organizational Citizenship Behaviour

Participation in decision making is linked to OCB in many ways. First, teachers' participation in decision making can enhance a sense of fairness and trust in the organization, as they can defend their own interests [8]. Teachers who view their institutions as behaving in their interest experience greater job satisfaction, and also act to return the favour by exhibiting more OCB [24]. Second, as teachers understand work processes and challenges better than administrators or policymakers, their participation ensures that better information is available for making decisions to facilitate successful teaching [12] and also they will get information on shaping their decisions which can enhance willingness to engage in OCB. To add more, procedural fairness in decision making exhibits OCB [26]. One of the most important conditions that shape employees' views about procedural fairness is participation in decision making [42].

Previous studies [29] [39] find employees perform OCB with greater frequency when they recognize organizations and their representatives make fair allocation decisions. Recent research suggests that teachers' participation in technical domain is associated with OCB towards students and teachers' participation in managerial domain has a positive effect on teachers' engagement in OCB towards students, team, and the organization [35]. 
B. Teachers' Participation in Decision Making and Commitment

Participation in decision making could create commitment through motivational mechanism. Research in general supports a link between participation in decision making and commitment [22]. Earlier research indicated a positive relation between teachers' participation in decision-making processes and their organizational commitment [16]. Research by Hoy, Tartar, and Bliss [20] finds higher commitment at institutions where principals acted on teachers' suggestions. Teachers' autonomy in making classroom decisions and participation in institution wide decision making shows a strong association with teacher commitment to the organization [18].

Review of literature reveals that most research examined the relationship between teachers' participation in decision making and organizational commitment [3]. This fact is supported by the recent study conducted by Somech and Bogler[35] who identified that the participation in the managerial domain is positively associated with organizational commitment. However, one might suggest that participation in the managerial domain reflects different motivations from participation in technical domain, fostering different dimensions of commitment. Thus, possible extension of the study is to examine the relationship between participation and other commitment variables, such as job involvement, and commitment to group.

\section{Teachers' Commitment and Organizational Citizenship Behaviour}

Given that the object of commitment is organization, the most likely behaviour to be affected by this commitment is organization oriented behaviour such as turnover intentions, actual turnover, [10], and organizational citizenship behaviour[11]. Similarly, the most likely behaviour to be affected by job involvement is task oriented behaviour such as absenteeism [6], organizational citizenship behaviour, and performance.

Review of the empirical literature [31] [44] has revealed that organizational commitment has mixed evidence regarding its relationship with OCB. On one hand, Schappe [31], and Schaubroeck and Ganster[32] have indicated a positive relationship between organizational commitment and OCB (i.e., teachers who are highly committed to their organization and/or to their profession are engaged in OCB) [35]. On the other hand, research by Williams and Anderson [44] found no significant relationship between organizational commitment and OCB. Nevertheless, Williams and Anderson [44] explicitly note that "organizational commitment deserves further consideration, because there is strong theoretical support for its impact on OCB" (p. 616). A few studies mention that the type of work-related commitment under consideration has some bearing on how commitment directs behaviour in organizations [34] [37]. Therefore, researchers should attempt to match the focus of their independent variable with the focus of their work outcome variable [5].

Based on the above arguments, it can be expected that OCB and in-role performance, as behaviours that are strongly linked to the organization, will be more strongly related to organization oriented commitments such as organizational commitment, group commitment, and job involvement [2]. Although most researchers have examined the relationship between organizational commitment and OCB [31] [44], there is a link missing between the forms of commitments, such as job involvement, group commitment and OCB in engineering colleges/institutes which requires attention. Moreover, using a multidimensional approach to OCB as well as to commitment might clarify the inconsistent findings in the literature on OCB [36]. While the OCB literature in non-educational settings is expansive, there are a few documented accounts of any causal relationship between organizational commitment and OCB of teachers, moreover, very little research exists regarding the effects of specific facets of organizational commitment on OCB, especially on OCB of teachers [45].

\section{Teachers' Participation in Decision Making, Commitment, and Organization Citizenship Behaviour}

One of the most important conditions that shape employees' view about the fairness of the procedure is participation in decision making, which is also called as process control effect [40]. Indeed, several studies have shown that participation in decision making lead to engagement in OCB, such as helping new members of the group [30]. Some other studies demonstrated that organizational commitment is related to behaviours that promote organizational effectiveness [23]. However, the opportunity to participate in decision making is not only related to OCB, but it is 
also related to individual's identification with, and involvement in the organization [13]. This organizational commitment is characterized by, among other things, a willingness to exert considerable effort on behalf of the organization [9].

Previous studies by Van Yperen et al. [42] explored to understand the mediating role of commitment in a relation between participation in decision making and OCB and found no meaningful link existing. On the other hand, the study conducted by [35] observed participation in the technical domain is associated with OCB towards students indirectly through professional commitment. They further suggested that enhancing teachers' opportunities to be involved in managerial issues can have a positive effect on organizational commitment, which in turn will increase teachers' engagement in OCB towards students, team, and the organization. The above findings have highlighted the importance of investigating participation in decision making, commitment, and organizational citizenship behaviour as a multidimensional concept. Examining the antecedents and determinants of each dimension separately in the context of engineering colleges/institutes is required.

\section{Objectives Of The Study And Hypotheses Development}

On the basis of the gaps found in the literature review, the following objectives have been formulated:

1. To examine relationship between the dimensions of participation in decision making and commitment variables, such as job involvement, group commitment, and affective organizational commitment.

2. To study the relationship between multiple commitments and multidimensional OCB.

3. To explore the relationship between participation in decision making and OCB.

Based on the above background the following hypothesis has been proposed:

H1(a): Participation in managerial domain will be positively related to affective organizational commitment.

H1(b): Participation in managerial domain will be positively related to group commitment.
H2(a): Participation in technical decisions will be positively related to job involvement.

H2(b): Participation in technical decisions will be positively related to group commitment.

H2(C): Participation in technical decisions will be positively related to affective organizational commitment.

H3:Job involvement will be positively related with organizational citizenship behaviour towards students.

H4(a): Affective organizational commitment will be positively related with organizational citizenship behaviour towards organization.

$\mathrm{H} 4(\mathrm{~b})$ : Affective organizational commitment will be positively related with organizational citizenship behaviour towards team.

H5(a):Group commitment will be positively related with organizational citizenship behaviour towards students.

H5(b):Group commitment will be positively related with organizational citizenship behaviour towards team.

H5(c):Group commitment will be positively related with organizational citizenship behaviour towards organization.

H6(a): Participation in technical decisions will be positively related with organizational citizenship behaviour towards students.

H6(b): Participation in technical decisions will be positively related with organizational citizenship behaviour towards team.

H6(c): Participation in technical decisions will be positively related with organizational citizenship behaviour towards organization.

H7(a): Participation in managerial decisions will be positively related with organizational citizenship behaviour towards students.

$\mathrm{H7}$ (b): Participation in managerial decisions will be positively related with organizational citizenship behaviour towards team.

H7(c): Participation in managerial decisions will be positively related with organizational citizenship behaviour towards organization.

\section{Method And Measures}

The respondents of this study were the teachers working in private engineering colleges affiliated to Jawaharlal Nehru Technological University 
Hyderabad, India. The participants consisted of Lecturers, Assistant Professors, Associate Professors, and Professors. The study was conducted with the help of questionnaires and the items were measured on a 5-point Likert scale. The study used SEM technique to verify the model.

The following measures were used for the study:

a) Participation in decision making was measured by Teachers' Involvement Scale,developed byBacharach, Bauer, and Shedd [4].

b) Affective organizational commitment was measured by Affective Organisational Commitment Scale,developed byMeyer and Allen [7].

c) Job involvement was measured by Job Involvement Scale,developed by Kanungo [21].

d) Group commitment was measured by Group Commitment Scale, developed by Ellemers, Gilder, and Heuvel[4].

e) Organizational citizenship behaviour was measured by Organisational Citizenship BehaviourScale, developed bySomech and DrachZahavy [12].

\section{Data Analysis Tools}

The Statistical Package for Social Sciences (SPSS) version 15.0 and the Analysis of Moments Structure (AMOS) version 16.0 were used to analyze the data. The statistical analyses included deriving the correlation and descriptive statistics. The Cronbach's alphas of the various measures used in the study were also reported. The structural model based on the hypotheses emerging out of the review of literature was subjected to analysis and fit tests. For this purpose a variety of Goodness-of-Fit indices as provided by AMOS 16.0 [2] were utilized. The competing models were tested and the conclusions regarding their acceptance were made. All the scales used for the study had desired level of psychometric properties i.e. validity and reliability of the scales were established.

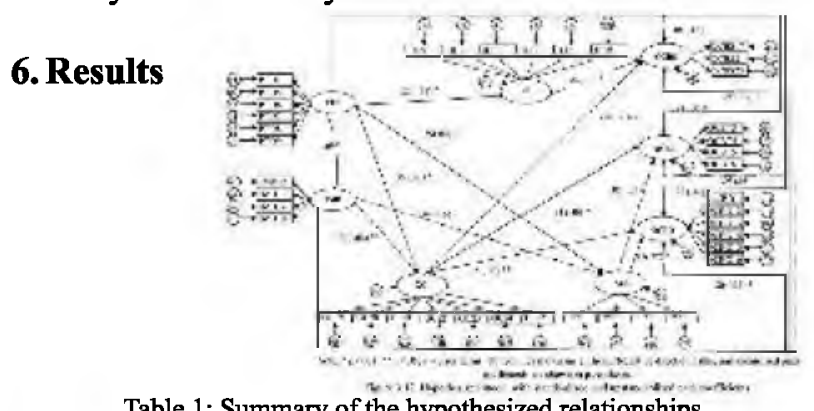

Table 1: Summary of the hypothesized relationships

\begin{tabular}{|c|c|c|c|}
\hline Hypothesized paths & $\begin{array}{l}\text { Beta }(\beta) \\
\text { estimate }\end{array}$ & $\begin{array}{l}\text { C.R./ } \\
\text { t-value }\end{array}$ & Decision \\
\hline H1(a): AOC?PMD & -.04 & -.55 & Refuted \\
\hline H1(b): GC? PMD & $-.13^{* *}$ & -2.08 & Refuted \\
\hline H2(a): JI ? PTD & $.23^{*}$ & 4.32 & Supported \\
\hline H2(b): GC ?PTD & $.35^{*}$ & 4.57 & Supported \\
\hline H2(c): AOC?PTD & $.39 *$ & 4.57 & Supported \\
\hline H3: OCBS? JI & $.36^{*}$ & 5.06 & Supported \\
\hline H4(a): OCBO?AOC & $.21^{*}$ & 3.39 & Supported \\
\hline H4(b): OCBT?AOC & .05 & .81 & Refuted \\
\hline H5(a): OCBS? GC & -.01 & -.14 & Refuted \\
\hline H5(b): OCBT? GC & $.31^{*}$ & 4.81 & Supported \\
\hline H5(c): OCBO?GC & $.15^{*}$ & 2.72 & Supported \\
\hline H6(a): OCBS ?PTD & .08 & .97 & Refuted \\
\hline H6(b): OCBT?PTD & $.32 *$ & 3.80 & Supported \\
\hline H6(c): OCBO ? PTD & $.25^{*}$ & 3.37 & Supported \\
\hline H7(a): OCBS?PMD & $.25^{*}$ & 3.32 & Supported \\
\hline H7(b): OCBT? PMD & .05 & .76 & Refuted \\
\hline H7(c): OCBO? PMD & $.26^{*}$ & 3.85 & Supported \\
\hline
\end{tabular}

Note: $\beta=$ standardized regression weight; ${ }^{* *} p<.05,{ }^{*} p<.001$.

\section{Discussion}

A. Objective 1: Participation - Commitment Relationship

Regarding the relationship between participation in decision making and commitment, the results demonstrate that participation in the technical decisions is positively associated with teachers' affective organizational commitment, job involvement, and group commitment. However, participation in the managerial decisions is not significantly associated with affective organizational commitment and was not positively associated with group commitment. This may be because of the fact that teachers have limited scope to participate in the managerial decisions at the institution level. Only a few teachers holding key positions get the opportunity to participate in the decisions related to determining the procedures to evaluate teachers' performance, setting and revising the institutional goal, etc. Such discrimination with respect to opportunity to participate in decision making affects teachers' attitude, and therefore, develops withdrawal intensions towards the group and the organization. 
Hence, teachers' participation in managerial decision making has not transformed to predict commitment to the group, and the organization.

Support for the above argument can also be obtained by verifying previous research. Taylor and Bogotch [38] reported low levels of teachers' involvement in the managerial issues such as designing administrative and organizational structure, developing methods to evaluate teachers, and setting institute goals, etc. It seems as part of the norms of the profession, technical issues fell within teachers' interest, whereas managerial issues fell outside it. Further, Bogler and Somech[7] find no influence of participation in decision making on the organizational commitment. However, they considered participation in decision making as a single dimension rather than two dimensions.

Concerning the positive relation between participation in the technical decisions and job involvement, the findings suggests involvement of teachers in the decisions related to students and classroom instructions were in congruence with their professional values and ethics. Teachers' influence in technical matters ensures that better decisions are made concerning to their own classroom which facilitates success in teaching.

Teachers' participation in technical domain involves consultation and exchange of ideas with their colleagues. Such activities would develop a sort of attachment with their colleagues. The reciprocity norm helps strengthen interpersonal relationships among teachers, which in turn helps teachers in developing group commitment. When a teacher in the group treats another teacher well, he or she is likely to receive the favorable treatment. When one employee treats another well, the norm of reciprocity obliges the return of favorable treatment [19].

When teachers are given an opportunity to participate in issues related to teaching, they may feel a sense of ownership with the institution. Meyer and Allen [7] suggest that affective commitment develops as a result of experiences that satisfy employee's need to feel physically and psychologically comfortable in the organization. Overall, the results support previous research, which suggests that work conditions are significant predictors of commitment [18] [35].

B. Objective 2: Commitment-OCB Relationship
The results indicate the positive association between commitment forms and OCB dimensions like affective organizational commitment and OCBO, job involvement and OCBS, and group commitment and OCBT, and OCBO.

Findings reveal that OCB towards organization is inspired by teachers' identification with the organization. A significant relationship has been found between affective organizational commitment and OCBO. Individuals who have a high level of affective organizational commitment will reciprocate to the organization by engaging in OCB [14] This suggests that teachers committed to the institutions are likely to exhibit behaviours which are beneficial to the institution. Thus, affectively committed teachers are more likely to be 'good citizens', relative to teachers who are not similarly attached to the institution. Allen and Meyer [1] expressed support for a theoretical linkage between organizational commitment and organizational citizenship behaviour. However, affective organizational commitment did not predict OCBS and OCBO. One of the reasons for such findings can be related to the dimensionality of OCB. A significant positive correlation between the dimensions of the OCB does not guarantee lack of inherent conflict between OCBS, OCBT, and OCBO as they all came from the same scale.

Positive relationship between job involvement and OCB towards students indicates that teachers perceive their main role as promoting students' learning and well-being. In other words, teachers work to improve classroom performance, enhance their ability to deal with students' discipline, and strengthen their awareness of the students' needs, etc. Therefore, teachers who are highly committed to their job will tend to make an extra effort. They stay beyond institutional timings to help students. This indicates that teachers committed to their job, work as professionals to promote students well-being.

Positive relationship between group commitment and OCB towards team and organization show that teachers understand their colleagues more than the students and the organization. When teachers identify themselves with the work group, they extend their support in managing the responsibilities of their colleagues. Helping other teachers who have heavy work load, helping an absent colleague by assigning learning tasks to the class, etc. are some of the citizenship behaviours that teachers exhibit. Teachers 
who are highly committed to their work group are also expected to engage in OCB towards organization. This is because socially involved individuals are usually reluctant to break social ties and they choose to perform by maintaining their membership with the institution.

Further results indicate that teachers who are highly committed to their job, organization, and to their group reported themselves to be engaged in OCB. These results support the theoretical models of Scholl [33] and Weiner [43] which suggest that commitment maintains behavioural direction. To be precise, job involvement is positively associated with OCB towards students. Affective organizational commitment is positively associated with OCB towards organization. Group commitment is positively associated with OCB towards team and organization.

Findings have demonstrated distinctive patterns of citizenship behaviour, corresponding to three levels of the institutional system: the student, the team, and the institution as a whole. These results provide support for the multidimensional approach to the conceptualization and measurement of citizenship behaviour. In the past, research focused mainly on a more global construct [28]. Present study provides some base for believing that citizenship behaviour is expressed differently in different domain of the institution. These results enhance the multidimensional approach to citizenship behaviour and also emphasize the importance of examining the antecedents of each construct separately.

\section{Objective 3: Participation-OCB Relationship}

Teachers' participation in decision making appears to be important in predicting the OCB dimensions. Participation in technical domain is positively associated with OCB towards team, and organization. Surprisingly, it is not significant predictor of OCBS. Similarly, participation in managerial domain is positively related with $O C B$ towards students and organization, but failed to predict OCBT. The reason for such findings can be explained by looking at the pattern of relationship between participation in decision making and organizational citizenship behaviour. Both, participation in technical decisions and participation in managerial decisions have predicted OCBO in common, but they are different in predicting OCBS and OCBT. Both OCBS and OCBT are the behaviours which are oriented towards individuals (i.e., towards students and colleagues) and hence there could be a sort of conflict between OCBS and OCBT dimensions as they both came for the same scale. Additionally, participation in managerial decisions failed to predict the group commitment, for the valid reasons that teachers do not have enough opportunity to participate in managerial decision making. This leads to withdrawal intensions and hence, was not translated to exhibit citizenship behaviours towards team.

Results suggest that by involving teachers in technical decisions, such as establishing students' disciplinary policies, deciding about standardized examination policy, etc. enhance a sense of fairness and trust in the institution. Allowing teachers to participate in such issues implies recognizing their domain expertise. When teachers succeed in defending their interests, they exhibit OCB towards team, and organization. Involving teachers in managerial decisions, such as designing infrastructure of the institution, setting and revising the goals of the institution, etc. gives them a feeling of expanding their knowledge from their classroom to the entire institution. Hence, teachers help students and the organization by demonstrating OCB.

\section{Conclusions}

The purpose of the study was to examine the impact of teachers' participation in decision making and commitment forms on their organizational citizenship behaviour. The relationship between participation in decision making and organizational citizenship behaviour reveals that teachers who are involved in decision making, whether on issues related to their own classroom or to the institution as a whole, will tend to exhibit OCB towards institution. These findings reinforce the importance of teachers' participation in decision making on both the domains because such participation affects OCB. Previous research supports a positive link between PDM and OCB. When teachers are invited to participate in decision making on issues related to technical and managerial they tend to demonstrate higher levels of OCB towards their students and colleagues and the institution as a whole. Thus, the institutions can benefit from the teachers' who exhibit citizenship behaviour.

The relationship between the teachers' 
commitment and citizenship behaviour stress the importance of enhancing teachers' identification and involvement with the job, the group, and the institution as a whole, as they can influence citizenship behaviours towards their students, colleagues, and the institution respectively. The findings suggest that commitment forms should be in congruence with different dimensions of $O C B$.

The study revealed the roles of affective organizational commitment and group commitment in explaining the teachers' participation in decision making and OCB relationship. With respect to the educational settings, the literature suggests that PDM promotes teacher and institutional outcomes through organizational commitment.

Findings also suggest that teachers are not much involved in decisions related to institutional operations and administration. The administrators should note that teachers' participation in managerial decisions is as important as participation in technical decisions for effective functioning of the educational institutions. Teachers in engineering institutions are capable of making decisions related to managerial domain as well. The findings advise that necessary steps may be taken to restructure teachers' role by involving them in decisions and activities that are part of the institutional life as a whole. Enhancing opportunities to participate in managerial issues can have a positive effect on teachers' commitment. Institutions having committed teachers will always have advantage over the institutions without such teachers. Scholars and practitioners concluded that the problems facing by educational institutions are big enough for any person to solve alone. Hence, by involving teachers in the process of decision making offers a variety of potential benefits to teachers, students, and the institutions alike. Participation strengthens the positive impact of PDM on teacher and institution outcomes.

Although OCB is not mandatory in job descriptions and are not formally rewarded, yet institutions need to recognize the importance of OCB for effective functioning. Administrators should also acknowledge the role of job involvement as a mediator and do something to increase it for better commitment. Findings also suggest that participation in decision making and organizational citizenship behaviour should be addressed as a multidimensional concept.

\section{Implications of The Study}

Findings of the present study are pertinent to concerned officials who are either directly or indirectly associated with the administration at different levels of governance of engineering institutions. Besides, exhibiting citizenship behaviours in both defined and undefined areas, teachers' involvement for performance is a must. Institutions need to consider empowering teachers to participate in all domains of decision making process, as it is not exclusively related to OCB but is also related to commitments, which in turn, influence teachers' OCB.

Head of the institutions should acknowledge the importance of the citizenship behaviours, since it carries advantage for other members in the institution, including teachers, students, and also to the institution as a whole. Findings showed teachers' participation in technical and managerial decisions predict dimensions of organizational citizenship behaviour. Participation in technical decisions plays important role in predicting organizational citizenship behaviour towards team and organization, whereas participation in managerial decisions indicate significant role in predicting organizational citizenship behaviour towards students and organization. Thus, practice of joint decision making should be recognized as highly important to the organization.

The institutions must provide supportive work environment, where teachers should sense that they have control over their job and related activities. Teachers who visualize institutions behaving in their favour can contribute more to the institution. Teachers will experience high status when they are allowed to participate in decisions related to their own classroom and the institution; such feelings would elevate their commitment forms. Therefore, head of the institutions should recognize the findings and have to make every effort to raise teachers' commitment to job, group, and the organization to increase their citizenship behaviours.

Finally, the findings of the study should also be acknowledged by the policy makers outside the institution based on the fact that teachers' participation in decision making and their commitment forms promote OCB. 


\section{Limitations Of The Study And Directions Of For Further Study}

The findings of the study should be interpreted considering a few limitations as given below:

1. Data were collected from engineering institutions affiliated to Jawaharlal Nehru University, Hyderabad, Andhra Pradesh. Researcher did not follow random sampling approach while collecting the data. However, precaution was taken to consider sample representation from all the three regions equally (rural, semi-urban, and urban). Considering the above limitations, implications of the study may be understood and applied with caution in other parts of the country.

2. The study assumed that commitment forms are the predictor of OCB but further research is needed to investigate these relationships to address the causality issue.

3. A combined quantitative and qualitative study might provide further insight into teachers' OCB.

4. The study is based on the data collected from teachers only, whereas the views of both the principals and teachers are equally important in order to understand better how each group conceives OCB.

5. Possible extensions of this study could be to examine the effects of other variables, such as job satisfaction, as mediating variables in the relationship between teachers' participation in decision making and organizational citizenship behaviour.

6. Finally, a comparison of OCB between Government and private colleges/universities can extend our understanding of the factors affecting the OCB in different educational settings.

\section{References}

[1] Allen, N. J., \& Meyer, J. P. (1996). Affective, continuance, and normative commitment to the organization: An examination of construct validity. Journal of Vocational Behaviour, 49, 252-276.

[2] Arbuckle, J. L., \&Wothke, W. (1999). AMOS 4.0 user's guide. Chicago: SPSS.

[3] Bacharach, S. B., Bamberger, P., Conley, S. C., \& Bauer, S. (1990). The dimensionality of decision participation in educational organization: The value of multi-domain evaluative approach.
Educational Administration Quarterly, 26, 126167.

[4] Bacharach, S. B., Bauer, S. C., \&Shedd, J. B. (1986). The learning workplace: The conditions and resources of teaching. (ERIC Document Reproduction Service No. ED279614)

[5] Becker, T. E. (1992). Foci and bases of commitment: Are they distinctions worth making? Academy of Management Journal, 35, 232-244.

[6] Blau, G. J. (1986). Job involvement and organizational commitment as interactive predictors of tardiness and absenteeism.Journal of Management, 12, 577-584.

[7] Bogler, R., \&Somech, A. (2004). Influence of teacher empowerment on teachers' organizational commitment, professional commitment and organizational citizenship behavior in schools. Teaching and Teacher Education, 20, 277-289.

[8] Bogler, R., \&Somech, A. (2005). Organizational citizenship behavior in schools: How does it relate to participation in decision making? Journal of Educational Administration, 43, 420-438.

[9] Brief, A. P., \&Motowidlo, S. J. (1986). Prosocial organizational behaviours.Academy of Management Review,11, 710-725.

[10] Cohen, A. (1993). Work commitment in relation to withdrawal intentions and union effectiveness. Journal of Business Research, 26, 75-90.

[11]Cohen,A.(2006). The relationship between multiple commitments and organizational citizenship behavior in Jewish and Arab culture.Journal of Vocational Behaviour, 69, 105118.

[12] Conley, S. C., \& Bacharach, S. B. (1990). From school-site management to participatory schoolsite management.Phi Delta Kappan, 71, 539-544.

[13]Cropanzano, R., \&Folger, R. (1996). Procedural justice and worker motivation. In Steers R. M., Porter L.W., \& G. A. Bigley (Eds.), Motivation and leadership at work (pp.72-83). New York: McGraw-Hill.

[14]Cropanzano, R., Rupp, D. E., \& Byme, Z. S. (2003). The relationship of emotional exhaustion to work attitudes, job performance, and organizational citizenship behaviors. The Journal of Applied Psychology, 88, 160-169.

[15]Diefendorff, J., Brown, D., Kamin.,\& Lord, B. (2002). Examining the roles of job involvement and work centrality in predicting organizational 
citizenship behaviours and job performance.Journal of Organizational Behavior, 23,93-108.

[16]Diosdado, M. S. M. (2008). Creating better schools through democratic school leadership. International Journal of Leadership in Education, 11,43-62.

[17] Ellemers, N., de Gilder, D., \& van den Heuvel, H. (1998). Career oriented versus team oriented commitment and behaviour at work. Journal of Applied Psychology,83, 717-730.

[18]Firestone, W. A., \& Pennell, J. R. (1993). Teacher commitment, working conditions, and differential incentive policies.Review of Educational Research, 63, 489-525.

[19]Gouldner, A. W. (1960). The norm of reciprocity: A preliminary statement. Americian Sociological Review, 25, 161-178.

[20]Hoy, W. K., Tartar, C. J., \& Bliss, J. R. (1990). Organizational climate, school health, and effectiveness: A comparative analysis. Educational Administration Quarterly, 26, 260279.

[21]Kanungo, R. N. (1982). Measurement of TUB and work involvement. Journal of Applied Psychology, 67,341-349.

[22]Louis, K. S., \& Smith, B. (1992). Cultivating teacher engagement: Breaking the iron law of social class. In Newmann, F. (Ed.), Student engagement and achievement in American secondary schools (pp. 119-152). New York: Teachers College Press.

[23]Mayer, R. C., \& Schoorman, F. D. (1992). Predicting participation and production outcomes through a two-dimensional model of organizational commitment. Academy of Management Journal, 35, 671-684.

[24]McNeely, B. L., \&Meglino, B. M. (1994). The role of dispositional and situational antecedents in prosocial organizational behaviour: An examination of the intended beneficiaries of prosocial behaviour. Journal of Applied Psychology, 79, 836-844.

[25]Meyer, J. P., \& Allen, N. J. (1991). A threecomponent conceptualization of organizational commitment.Human Resource Management Review, 1, 61-89.

[26]Moorman, R. H., Blakely, G. L., \&Niehoff, B. P. (1998). Does perceived organizational support mediate the relationship between procedural justice and organizational citizenship behaviour. Academy of Management Journal, 41, 351-357.

[27]Munene, J. C. (1995). 'Not-on-seat': An investigation of some correlates of organizational citizenship behaviour in Nigeria. Applied Psychology: An International Review, 44, 111112.

[28]Organ, D. W. (1988). Organizational citizenship behaviour: The good soldier syndrome. Lexington, MA: Lexington Books.

[29]Podsakoff, P. M., MacKenzie, S. B., Paine, J. B., \& Bacharach, D. G. (2000). Organizational citizenship behaviors: A critical review of the theoretical and empirical literature and suggestions for future research. Journal of Management, 26, 513-563.

[30]Porter, L. W., Lawler, E. E. III., \& Hackman, J. R. (1996). Ways groups influence individual work effectiveness. In Steers, R. M., Porter, L. W., \&Bigley, G. A. (Eds.), Motivation and leadership at work (pp. 346-354), New York: McGraw-Hill.

[31]Schappe, S. P. (1998). The influence of job satisfaction, organizational commitment, and fairness perceptions on organizational citizenship behaviour.Journal of Psychology, 132, 277-290.

[32]Schaubroeck, J., \& Ganster, D. C. (1991). Beyond the call to duty: A field study of extra-role behaviour in voluntary organization. Human Relations, 44, 569-582.

[33] Scholl, R. W. (1981). Differentiating organizational commitment from expectancy as a motivating force.Academy of Management Review, 6, 589-599.

[34]Siders, M. A., George, G., \&Dharwadkar, R. (2001). The relationship of internal and external commitment foci to objective performance measures.Academy of Management Journal, 44, 570-579.

[35]Somech, A., \&Bogler, R. (2002). Antecedents and consequences of teacher organizational and professional commitment.Educational Administration Quarterly,38, 555-577.

[36]Somech, A., \&Drach-Zahavy, A. (2000). Understanding extra-role behaviour in schools: The relationships between job satisfaction, sense of efficacy, and teachers' extra-role behaviour. Teaching and Teacher Education, 16, 649-659.

[37]Somers, M. J., \& Birnbaum, D. (1998). Workrelated commitment and job performance: It's also the nature of the performance that counts. 
Journal of Organizational Behaviour, 19, 621-634.

[38]Taylor, D. L., \&Bogotch, J. E. (1994). Schoollevel effects of teachers' participation in decision making.Educational Evaluation and Policy Analysis, 16, 302-319.

[39]Tepper, B. J., \& Taylor, E .C. (2003). Relationships among supervisors' and subordinates' procedural justice perceptions and organizational citizenship behaviours.Academy of Management Journal, 46, 97-105.

[40]Thibaut, J., \& Walker, L. (1975). Procedural justice: A Psychological analysis. Hillsdale, NJ: Lawarance Erlbaum Associates.

[41]Umashankar, V., \&Dutta, K. (2007). Balanced scorecards in managing higher education institutions: An Indian perspective. International Journal of Educational Management, 21, 54-67.

[42]VanYperen, N. W., Berg, A. E., \& Willering, M. C.
(1999). Towards a better understanding of the link between participation in decision making and organizational citizenship behaviour: A multilevel analysis. Journal of Occupational and Organizational Psychology, 72, 377-392.

[43] Weiner, Y. (1982). Commitment in organizations: A normative view. Academy of Management Review, 7, 418-428.

[44]Williams, L. J., \& Anderson, S. E. (1991). Job satisfaction and organizational commitment as predictors of organizational citizenship and inrole behaviour.Journal of Management, 17, 601617.

[45]Zeinabadi, H. (2010). Job satisfaction and organizational commitment as antecedents of organizational citizenship behavior of teachers.Procedia Social and Behavioral Sciences, 5, 998-1003. 